\title{
Clinical Results of Photodynamic Therapy for Superficial Skin Malignancies or Actinic Keratosis Using Topical 5-Aminolaevulinic Acid
}

\author{
P.J.N. MEIJNDERS ${ }^{a}$, W.M. STAR ${ }^{b}$, R.S. DE BRUIJN ${ }^{b}$, A.D. TREURNIET-DONKER ${ }^{a}$, \\ M.J.M. VAN MIERLO' ${ }^{a}$, S.J.M. WIJTHOFF ${ }^{c}$, B. NAAFS ${ }^{d}$, H. BEERMAN ${ }^{e}$, P.C. LEVENDAG ${ }^{a}$ \\ ${ }^{a}$ Department of Radiotherapy, Dr. Daniel den Hoed Cancer Centre, Rotterdam, The Netherlands \\ ${ }^{b}$ Department of Clinical Physics (Photodynamic Therapy Laboratory), Dr. Daniel den Hoed Cancer Centre, Rotterdam, \\ The Netherlands \\ ${ }^{c}$ Department of Plastic Surgery, Dr. Daniel den Hoed Cancer Centre, Rotterdam, The Netherlands \\ ${ }^{d}$ Department of Dermatology, Dijkzigt Hospital, University Hospital, Rotterdam, The Netherlands \\ ${ }^{e}$ Department of Pathology, Dr. Daniel den Hoed Cancer Centre, Rotterdam, The Netherlands \\ Correspondence to W. M. Star, Dr. Daniel den Hoed Cancer Centre, University Hospital Rotterdam, P.O. Box 5201, 3008 AE \\ Rotterdam, The Netherlands \\ Paper received 11 April 1996
}

\begin{abstract}
Photodynamic therapy (PDT) with topical application of 5-aminolaevulinic acid (ALA, $20 \% \mathrm{w} / \mathrm{w}$ ) was used to treat superficial basal cell carcinoma (BCC, 16 patients), Morbus Bowen (one patient), basal cell naevus syndrome (BCNS, three patients), actinic keratosis (AK, two patients), chronic inflammation (CI, one patient), and metastasized BCC (one patient). The interval between ALA application and illumination was $3-6 \mathrm{~h}$. The incident light dose was $50-100 \mathrm{~J} \mathrm{~cm}{ }^{-2}$, mostly $75 \mathrm{~J} \mathrm{~cm}^{-2}$, at $633 \mathrm{~nm}$ wavelength. This was based on the fluorescence excitation spectrum, measured on the skin of human volunteers. In a few cases, $514.5 \mathrm{~nm}$ light was used. A complete response (CR) rate of 79\% (median follow-up 13 months) was obtained with 42 BCC lesions. The treatment of five areas with $\mathrm{AK}$, two areas with $\mathrm{CI}$ and one area with M. Bowen yielded three CR for AK and five partial remissions (PR). Photodynamic therapy of metastasized BCC, after either topical or oral ALA, was not successful. Treatment of BCNS was satisfactory with $100 \%$ CR in one patient (22 lesions), PR in a second patient (20 lesions), and good palliation in a third patient (>250 lesions). The treatment was well tolerated, although the illumination had to be interrupted occasionally due to pain. Healing usually occurred in 2 weeks. Cosmetic results were good to excellent. 5-Aminolaevulinic acid application over $16-19 \mathrm{~h}$ and repeated treatments made it possible to obtain CR of non-superficial lesions. The selective tumour fluorescence was then lost, however, due to fluorescence of normal skin, but the cosmetic outcome did not deteriorate. 5-Aminolaevulinic acid PDT may be a good alternative outpatient treatment, especially in elderly patients and for large treatment areas. The excellent cosmetic outcome warrants further study in younger patients. More work is necessary to establish optimal ALA-treatment schemes.
\end{abstract}

\section{INTRODUCTION}

Primary skin cancer is the most common malignancy in man, which can usually be treated successfully by several modalities, such as surgical excision, cryotherapy or radiotherapy (1). All modalities have their specific advantages and disadvantages, still leaving room for improvement. Furthermore, when treatment modalities achieve a nearmaximal result (cure), side issues become more important, such as overall treatment time, complications and cosmetic results.

Photodynamic therapy (PDT) is a new cancer treatment modality that is particularly suited to the treatment of superficial malignancies. The basis of PDT is the use of a non-toxic drug, a photosensitizer, which after accumulation in the target tissue is photo-activated in situ. The resultant photochemical reaction releases highly reactive singlet oxygen which is cytotoxic (2). This process is non-selective 
in principle, and tumour specificity depends on a relatively high accumulation of the photosensitizer in tumour tissue after systemic administration, combined with well-directed illumination. The most widely studied photosensitizer is Photofrin, a drug that has been approved for a limited number of clinical indications in Canada, The Netherlands, Japan and the USA. Photodynamic therapy using Photofrin and superficial illumination has resulted in complete response (CR) rates of $88 \%$ (3) and $96 \%$ (4) for basal cell carcinomas (BCC), and near $100 \%$ CR for Bowen's disease $(5,6)$. Although Photofrin is a potent photosensitizer, a major side-effect is prolonged cutaneous photosensitivity compelling patients to avoid exposure to direct sunlight or bright daylight for 4-6 weeks after treatment $(7,8)$. Therefore, PDT with a standard dose of Photofrin $\left(2 \mathrm{mg} \mathrm{kg}^{-1}\right)$ is not an ideal treatment for primary skin cancer. Reduction of the Photofrin dose to $1 \mathrm{mg} \mathrm{kg}^{-1}$ (3) improves the therapeutic ratio, but does not solve the problem of skin photosensitivity completely.

An alternative form of PDT, avoiding generalized skin phototoxicity, has been introduced by Kennedy et al (9), using endogenous photosensitization by topically applied 5aminolaevulinic acid (ALA). 5-Aminolaevulinic acid is a precursor of protoporphyrin IX (PpIX) in the biosynthetic pathway for haem. Several steps in this pathway are rate-limited and tightly regulated. The feedback mechanisms can be bypassed by administering excess amounts of exogenous ALA, resulting in an accumulation in the cells of PpIX, an effective photosensitizer. Exposure to photo-activating light of appropriate wavelength and dose generates a characteristic red fluorescence and phototoxic cell damage $(10,11)$. This form of PDT will be called ALA-PDT. Kennedy reported a $\mathrm{CR}$ rate of $79 \%$ for superficial $\mathrm{BCC}$ after one illumination (12), following topical application for $3-6 \mathrm{~h}$ of $20 \%$ ALA in an oil-inwater emulsion.

The authors' interest in ALA-PDT started when a patient with basal cell naevus syndrome (BCNS), having extensive BCC lesions, was presented for PDT. This patient had been treated with all conventional modalities which were ineffective. Photofrin-PDT would involve photosensitization of this patient for a long time, because of the many lesions requiring treatment. The response of this patient to topical ALA-PDT was so encouraging that a clinical study of ALA-PDT for superficial BCC and actinic keratosis was started. The results of this study on 23 patients are reported in this paper.

\section{MATERIALS AND METHODS}

\section{5-Aminolaevulinic acid and solvent}

The ALA was supplied by Janssen Pharmaceuticals, Beerse, Belgium. Initially, a cream obtained from the hospital pharmacy ('Lanette') was used as solvent. Instillagel ${ }^{\mathbb{B}}$ was later used which has a lower viscosity and contains $2 \%$ lidocaine.

\section{Protoporphyrin IX fluorescence excitation spectrum}

At the start of this study, nothing was known about the action spectrum for PDT with endogenousiy generated PpIX. Determining an in vivo action spectrum with an accuracy that yields a wavelength resolution better than $5 \mathrm{~nm}$ involves a considerable amount of work, as was shown by the authors' study on the action spectrum for Photofrin-PDT (13). However, for Photofrin-PDT it appeared that the in vivo absorption spectrum, the fluorescence excitation spectrum and the PDT-action spectrum all had a maximum at $625 \mathrm{~nm}$ (14). Therefore, since a similar coincidence of maxima might occur for PpIX, the in vivo fluorescence excitation spectrum of PpIX was measured. This measurement can be made accurately and relatively easily. 5-Aminolaevulinic $(20 \%)$ was applied to two areas of $1 \mathrm{~cm}^{2}$ on the skin (arm) of three volunteers. The application time before measurement of one spot was $5-6 \mathrm{~h}$, and of the other spot was $18 \mathrm{~h}$. The fluorescence was excited with light from an argon pumped dye laser (620 $650 \mathrm{~nm}, 1 \mathrm{~nm}$ linewidth) at intervals, between 620 and $650 \mathrm{~nm}$, of $5 \mathrm{~nm}$, and $2.5 \mathrm{~nm}$ near the maximum using an irradiance of $0.1 \mathrm{~mW} \mathrm{~cm} \mathrm{~cm}^{-2}$. The wavelengths were selected with a monochromator that was calibrated against a He-Ne laser. Fluorescence was also excited with the argon laser at wavelengths of $488,496.5,501.7$ and $514.5 \mathrm{~nm}$. The fluorescence was measured with a digital intensified CCD camera, through a $700 \pm 20 \mathrm{~nm}$ band pass filter.

\section{Photodynamic therapy}

Local Ethical Committee approval was obtained for this study, as was individual 
informed consent. Patients were recruited from the Department of Dermatology, University Hospital Rotterdam, Dijkzigt, The Netherlands, and from the Departments of Plastic Surgery and Radiotherapy of the Daniel den Hoed Cancer Centre, Rotterdam, The Netherlands. Patients with clinically superficial lesions ( $\leq 3 \mathrm{~mm}$ thickness) were considered eligible. Most lesions were very superficial $(<1 \mathrm{~mm})$. Biopsies were obtained from single lesions before treatment. In case of multiple lesions, only two or three representative lesions were biopsied. Patients with histologically confirmed BCC, Morbus Bowen or actinic keratosis were included in this study. Twenty-three patients were treated with ALA-PDT, 10 males and 13 females, with a mean age of $65 \mathrm{yr}$ (range 35-89 yr).

Lesions were examined and measured carefully, and crusts were removed. A 20\% ALA solution (w/w) was applied to the lesion plus a margin of approximately $5-10 \mathrm{~mm}$ of apparently normal skin. The area was covered with a very thin gauze soaked in ALA solution, as a form of ALA reservoir, and was occluded with Tegaderm ${ }^{\mathbb{B}}$. The first 16 patients were treated after an ALA application time of 3-6 h, which was extended to $16-19 \mathrm{~h}$ for some later patients and for retreatments. The non-absorbed cream was wiped from the skin just before illumination with $633 \mathrm{~nm}$ light (see Results) from an argon pumped dye laser (Spectra Physics $2040 \mathrm{E}$ and $375 \mathrm{~B}$, respectively). In a few cases of very superficial lesions, $514.5 \mathrm{~nm}$ light from the argon laser was used. The light was focused into a $600 \mu \mathrm{m}$ diameter optical fibre, guided to the treatment room and imaged through a lens system to produce a circular treatment field with a uniform light intensity. The irradiance, measured with a Spectra Physics SP407 power

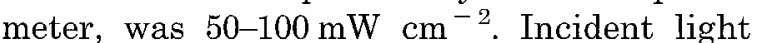
doses of $50-100 \mathrm{~J} \mathrm{~cm}^{-2}$ were applied (mostly $75 \mathrm{~J} \mathrm{~cm}{ }^{-2}$ ). The PpIX fluorescence was either measured during treatment or visually observed through a coloured glass filter (Schott RG665). At the end of the illumination, the fluorescence was always photobleached completely. Treatment fields were typically $3-8 \mathrm{~cm}$ in diameter, and the treatment times were $10-30 \mathrm{~min}$.

After treatment, patients were seen in the outpatient clinic at regular intervals for evaluation. Tumour responses and cosmetic results were scored clinically and by evaluation of colour photographs, which were taken before treatment and during the follow-up of every

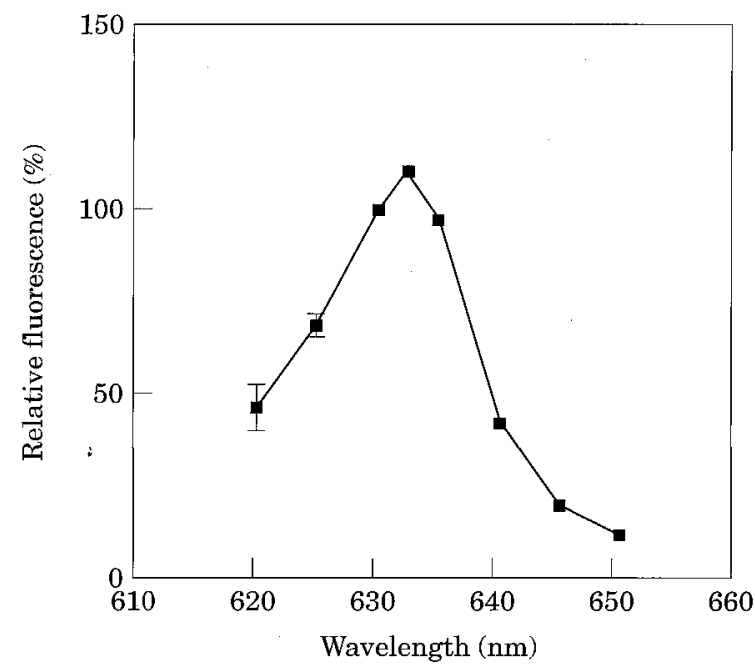

Fig. 1. Fluorescence excitation spectrum from $620 \mathrm{~nm}$ to $650 \mathrm{~nm}$ of 5-aminolaevulinic-acid-induced protoporphyrin IX in normal human skin in vivo. Emission was measured in a band of $700 \pm 20 \mathrm{~nm}$. Mean of six spots, three subjects. The data from all spots were normalized to 100 at $630 \mathrm{~nm}$. If no error bar is visible, it is smaller than a solid square.

patient. A CR was defined as absence of clinically evident tumour at the site of treatment after 2-3 months. Partial response was defined as at least $50 \%$ reduction in tumour size. Progressive disease (PD) is at least $25 \%$ tumour growth, and otherwise the response was classified as stable disease (SD). The mean followup for all patients was 17 months (range 1-54 months); for the BCC patients only, this was 13 months (range 1-39 months).

The cosmetic outcome of the CR lesions was classified as excellent (absence of any visible sign of lesion or stigmata of treatment), good (slightly visible), fair (moderate discoloration) or poor (strong hyperpigmentation) in the treatment area.

\section{RESULTS}

\section{Protoporphyrin fluorescence excitation spectrum}

The PpIX fluorescence excitation spectrum in the red spectral region in the healthy volunteers is shown in Fig. 1. The maximum is at $633 \pm 1 \mathrm{~nm}$. There was no measurable difference between the fluorescence excitation spectra after 5-6 h and $18 \mathrm{~h}$ ALA application time. Therefore, these data were taken together and the average was plotted in Fig. 1. The available argon laser lines could not define the local fluorescence excitation maximum. For 
Photofrin, this maximum is close to $500 \mathrm{~nm}$ (15). For PpIX, the fluorescence increased with increasing wavelength but showed a tendency to flatten at $514.5 \mathrm{~nm}$ (data not shown). For PpIX, the maximum may therefore be at or slightly above $514.5 \mathrm{~nm}$.

\section{Photodynamic therapy}

The treatment was generally well tolerated. However, on several occasions, the illumination had to be interrupted or the irradiance reduced due to pain. The authors now often start the treatment with $50 \mathrm{~mW} \mathrm{~cm}^{-2}$ irradiance, which is gradually increased to $100 \mathrm{~mW}$ $\mathrm{cm}^{-2}$ as the treatment progresses and the PpIX-fluorescence is photobleached. It appeared to the authors that after 16-19 h of ALA application, more patients complained about pain and the pain was more intense. Emla ${ }^{\circledR}$ ointment, oral pain relievers (paracetamol, naproxen or tramadol) or lidocaine infiltration were applied with varying success. After illumination, the treated area was usually reddish and slightly swollen, and sometimes some serous exudation was seen during and after illumination. A crust usually developed, which fell off within 14 days. Healing rarely took more than 3 weeks. Redness or pigmentation may take a few months to disappear, usually without a visible scar.

\section{Basal cell naevus syndrome (BCNS)}

Multiple lesions in three patients with BCNS were treated in numerous sessions. In one patient, all treated lesions (22 in 10 light fields) showed a CR. This patient was illuminated with $100 \mathrm{~J} \mathrm{~cm}^{-2}$ of green light $(514.5 \mathrm{~nm})$ at $150 \mathrm{~mW} \mathrm{~cm}{ }^{-2}$. The patient felt itching rather than pain. The response was strong; pigmentation remained for months but all lesions eventually healed scar-free. In the second patient, the most active lesions were treated, resulting in a CR or PR. Although most lesions did not disappear completely clinically, they remained quiescent for at least 15 months. The third patient has already been mentioned in the introduction. This patient had so many lesions that only a few of the most active ones could be treated in one session. The best result in this patient was palliation using ALA-PDT and, occasionally, cryotherapy or plastic surgery. Lesion thickness ranged from very superficial to thick (several $\mathrm{mm}$ ). All types of response occurred after one or more treatments by ALAPDT. Numerous lesions were retreated several times over more than $5 \mathrm{yr}$ (total>250). In this patient, CR of a few non-superficial lesions could be obtained by three or more ALA-PDT treatments over several weeks. Occasionally, milia developed in areas that were treated repeatedly, which may be regarded as an adverse cosmetic result.

\section{Basal cell carcinoma (BCC)}

Forty-two superficial BCCs were treated in 16 patients. The results are summarized in Table 1. An initial CR rate of $81 \%$ (34 of 42 lesions) was seen with only one recurrence after 14 months, so the recurrence-free $\mathrm{CR}$ rate is $79 \%$ (33 of 42 lesions). In 19\% (eight of 42 lesions), only a PR was achieved (follow-up 1-39 months, average 13 months). In one patient, a lesion with a poorly-defined boundary developed a recurrence at the edge of the treatment field. The cosmetic result was usually good to excellent, and tiny scars developed only in skin already damaged by the tumour.

\section{Morbus Bowen}

One patient with M. Bowen on the back of the left fifth finger and adjacent hand was accepted for ALA-PDT, although clinically there was some doubt whether certain areas showed a beginning of infiltrative growth. The maximal response was seen after 2 months with $>90 \%$ reduction in tumour area, which was approximately $5 \mathrm{~cm}^{2}$ before PDT. Only a small crust of about $5 \mathrm{~mm}$ remained. Subsequently, the tumour started growing again, and barely responded to a second ALA-PDT treatment. Subsequent treatment with radiotherapy (54 Gy) produced a CR.

\section{Actinic keratosis}

Three patients, two with extensively pretreated lesions, received ALA-PDT. One patient had lesions of actinic keratosis in an area adjacent to delicate skin on the skull, $2 \mathrm{yr}$ after radiotherapy for an ulcerating BCC. The lesion showed a CR without damage to the irradiated skin. The second patient had multiple lesions on the skull, treated extensively 
Table 1. Results of ALA-PDT in patients with superficial skin lesions

\begin{tabular}{|c|c|c|c|c|c|c|}
\hline & $\begin{array}{c}\text { No. } \\
\text { of } \\
\text { patients }\end{array}$ & $\begin{array}{c}\text { No. } \\
\text { of } \\
\text { lesions }\end{array}$ & $\mathrm{CR}$ & PR & PD & $\begin{array}{c}\text { Recurrence } \\
\text { after CR }\end{array}$ \\
\hline BCNS & 2 & $>250$ & $a$ & $\alpha$ & $\alpha$ & $a$ \\
\hline $\mathrm{BCNS}^{b}$ & 1 & 22 & $22(100 \%)$ & & & \\
\hline $\mathrm{BCC}$ & 16 & 42 & $34(81 \%)^{c}$ & $8(19 \%)$ & & $1(3 \%)$ \\
\hline Actinic keratosis & 3 & 5 & $3(60 \%)^{c}$ & $2(40 \%)$ & & $1(20 \%)$ \\
\hline Chronic & 1 & 2 & & $2(100 \%)$ & & \\
\hline Inflammation & & & $:$ & & & \\
\hline Morbus Bowen & 1 & 1 & & $1(100 \%)$ & & \\
\hline Metastasized BCC & 1 & 8 & & & $8(100 \%)$ & \\
\hline
\end{tabular}

ALA-PDT, 5-aminolaevulinic acid photodynamic therapy; $\mathrm{CR}$, complete response; $\mathrm{PR}$, partial response; $\mathrm{PD}$, progressive disease; $\mathrm{BCNS}$, basal cell naevus syndrome; $\mathrm{BCC}$, basal cell carcinoma.

${ }^{a}$ All types of responses were seen; a few areas treated with green light $(514.5 \mathrm{~nm})$.

${ }^{b}$ Treated only with green light $(514.5 \mathrm{~nm})$.

${ }^{c}$ Not corrected for recurrence.

with conservative methods (ointments), surgery and cryotherapy. Two ulcers appeared to be due to chronic inflammation. All actinic keratotic lesions disappeared after ALA-PDT. The chronic ulcers showed some regression which further improved after conservative treatment. The third patient had resistant actinic keratosis just cranial to his left eyebrow, responding nearly completely to one ALA-PDT session. Eight months later, recurrence was seen, which responded incompletely to a second ALA-PDT treatment. The lesion was excised surgically. Histology showed extensive actinic keratosis but also foci of infiltrating squamous cell carcinoma.

\section{Oral 5-aminolaevulinic acid}

One patient presented for ALA-PDT after extensive surgery and radiotherapy for metastasized BCC. After multiple recurrences in the frontal skin, lymph node metastases had developed. Later, intracutaneous metastases appeared in the face and in the neck. Surgery or radiotherapy were no longer possible for this disfigured patient. 5-Aminolaevulinic acid was given orally in orange juice $\left(50 \mathrm{mg} \mathrm{kg} \mathrm{kg}^{-1}\right.$ body weight) after which PpIX fluorescence of the skin which was particularly strong in the surgically-treated parts of the face could be observed. Eight areas were illuminated, started $4 \mathrm{~h}$ after ingestion of ALA $(16,17)$ and completed $3 \mathrm{~h}$ later. The patient felt pain in the areas on the face that showed strong fluor- escence, and some itching elsewhere. The response to PDT was insignificant, however, and later treatment with topical ALA-PDT was ineffective.

\section{DISCUSSION}

\section{Fluorescence excitation spectrum and ALA-PDT action spectrum}

On the basis of previous experience with Photofrin (14), the wavelength of the maximum in the in vivo PpIX fluorescence excitation spectrum, $633 \mathrm{~nm}$ for PpIX, was chosen as the optimum wavelength for ALA-PDT. Recently, Szeimies et al (18) studied the action spectrum for ALA-PDT both in vitro and in vivo. In vitro, the optimum wavelength was found to be $635 \pm 2 \mathrm{~nm}$. In this regard, the possibility of a small blue-shift from in vitro to in vivo should be considered $(13,14)$. In vivo, only the difference between $630 \mathrm{~nm}$ and $635 \mathrm{~nm}$ was detected, $635 \mathrm{~nm}$ being more effective (18). Considering the experimental errors, the difference with the results of the present paper is not significant. In clinical practice, the difference between the ALA-PDT effect at $633 \mathrm{~nm}$ and at $635 \mathrm{~nm}$ would probably not be measureable.

For truly superficial lesions, green light $(514.5 \mathrm{~nm})$ from the argon laser may be a good alternative for red light, if a laser is available. Because of the high power available, this could make it possible to treat large areas in a relatively short time. 


\section{Clinical results of ALA-PDT}

This study confirms that ALA-PDT can have a role in the curative and palliative treatment of superficial pre-malignant skin lesions, although it must compete with highly successful standard treatments. With cryotherapy or surgery, a $9095 \%$ success rate is usually achieved for small lesions (19-23). Similar high cure rates can be achieved with fractionated radiotherapy. For good cosmetic results, this requires an overall treatment time of 3-4 weeks (24). Radiotherapy is a highly successful therapy for larger superficial as well as deeply invasive lesions, for lesions in anatomical areas not easily accessible for surgery, and in patients with relative or absolute contraindications to surgery.

The present results are in the same range as reported by other authors, although the number of patients is relatively small. For treatment of $\mathrm{BCCs}$, a CR rate of $81 \%$ was achieved 3 months after treatment. Kennedy et al (9) reported $90 \% \mathrm{CR}$ for $\mathrm{BCCs}$ after 2-3 months, and $79 \%$ in a more recent paper (12). Cairnduff (25) achieved a CR of $88 \%$, which fell to $50 \%$ after 17 months follow-up. This result was influenced considerably by the negative selection of her patients. Most patients referred for ALA-PDT were elderly people and had large lesions, considered less suitable for standard treatment. Several other studies have been published recently, reporting $80-100 \%$ CR for superficial BCCs (26-29). Nodular $\mathrm{BCCs}$ generally require multiple treatments to achieve CR.

One patient with M. Bowen was treated with PR as best result, although the response was quite significant (see Results). Clinically, there was some doubt whether certain areas showed early infiltrative growth, but this was not confirmed in biopsies. Possibly, ALA-PDT failed in the thickest areas. Cairnduff (25) and Calzavara-Pinton (26) reported excellent results for patients with $\mathrm{M}$. Bowen $(89 \% \mathrm{CR}$ after 18 months, and $100 \% \mathrm{CR}$, respectively), showing that $M$. Bowen is a good indication for ALA-PDT.

The patients with actinic keratosis all had a history of different therapies, not resulting in a CR. In one patient, ALA-PDT gave an excellent $\mathrm{PR}$, resulting in only a tiny remaining spot of $2 \mathrm{~mm}$ diameter. Ten months later, however, a recurrence appeared which did not respond to a second ALA-PDT treatment. After surgical excision, a squamous cell carcinoma appeared in one spot, indicating again that in the course of the disease, malignant degeneration can occur, a possibility which should always be borne in mind.

The present results with three BCNS patients were satisfying. The $22 \mathrm{BCCs}$ of one patient all responded completely. The second patient had multiple lesions all over his body. Treatment of the most active lesions resulted in a clinical PR, and the appearance of the treated lesions showed no sign of progression after 15 months of follow-up. The third patient had extensive disease with BCCs all over the head, trunk and arms, confluent in areas treated previously with radiotherapy. For this patient, ALA-PDT has provided satisfactory palliation, with a CR of many superficial lesions. The main goal of treatment is palliation, which can be achieved only with the help of cryotherapy and surgery for the larger lesions. In order to improve the response of non-superficial lesions, ALA was applied overnight (16-19 h). This appeared to improve ALA penetration and thus the depth of treatment. By repeated treatments using overnight ALA application, complete responses of some nonsuperficial BCCs could be achieved. Selective tumour fluorescence, observed after $46 \mathrm{~h}$ ALA application (Fig. 2), was absent in this patient after $16-19 \mathrm{~h}$ application, because the ALA-exposed normal skin showed as much fluorescence as the tumour. Nevertheless, the cosmetic result following PDT was not affected adversely.

Encouraged by these results, seven patients with BCCs were treated after $16 \mathrm{~h}$ of ALA application (Table 2). This avoids waiting $3-6 \mathrm{~h}$, since the ALA is applied in the late afternoon and the illumination is done the next day. Although the selective tumour fluorescence was lost, the cosmetic result did not deteriorate. No telangiectasia, fibrosis or contractions were seen. However, the authors had the strong impression that the patients felt more pain during treatment after $16 \mathrm{~h}$. This is likely to be the result of increased ALA penetration $(30,31)$. Also, fluorescence was observed in normal adjacent skin after $12 \mathrm{~h}$ ALA application (30). Kennedy (4) did not observe ALA passage through normal keratin after $6 \mathrm{~h}$. The difference might be explained by a delayed penetration of the lipophilic stratum corneum by hydrophilic ALA. This would also explain the relative tumour selectivity after $4 \mathrm{~h}$ ALA application. 

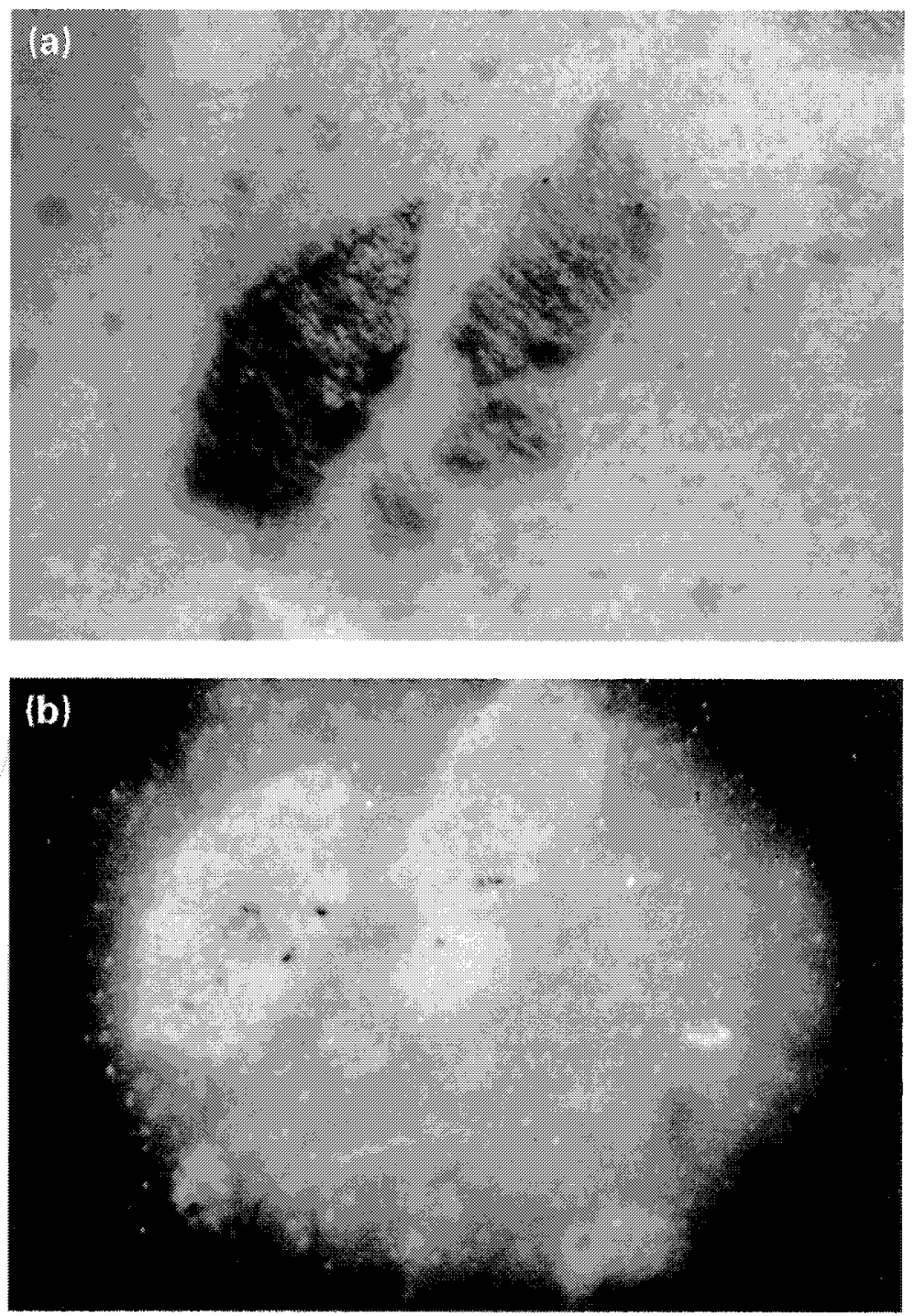

Fig. 2. (a) Photograph of two basal cell carcinoma ( $\mathrm{BCC}$ ) lesions on the chest wall of a basal cell naevus syndrome patient. (b) Fluorescence of the same lesion in (a) photographed through an RG665 coloured glass filter during illumination with green laser light $(514.5 \mathrm{~nm})$. The BCC lesions are demarcated clearly. The fluorescent dots are hair follicles. 5-aminolaevulinic acid (ALA) application time $\approx 4 \mathrm{~h}$. When the ALA application time was 16-19 h, selective tumour fluorescence was lost in this patient: the whole area where ALA had been applied showed nearly the same fluorescence intensity.

Table 2. Results with different ALA application times for 16 patients with BCC

\begin{tabular}{|c|c|c|c|c|c|}
\hline ALA application time & $\begin{array}{l}\text { No. of } \\
\text { patients }\end{array}$ & $\begin{array}{l}\text { No. of } \\
\text { lesions }\end{array}$ & CR & PR & $\begin{array}{c}\text { Recurrence } \\
\text { after CR }\end{array}$ \\
\hline $3-6 h$ & 9 & 32 & $25(78 \%)$ & $6(19 \%)$ & $1(3 \%)$ \\
\hline $16-19 \mathrm{~h}$ & 7 & 10 & $8(80 \%)$ & $2(20 \%)$ & $0(0 \%)$ \\
\hline Second ALA application ${ }^{\alpha}$ & 4 & 4 & 1. $(25 \%)$ & $3(75 \%)$ & $0(0 \%)$ \\
\hline
\end{tabular}

ALA, 5-aminolaevulinic acid; $\mathrm{BCC}$, basal cell carcinoma; CR, complete response; PR, partial response.

Two ALA applications of $4 \mathrm{~h}$, two applications of $16 \mathrm{~h}$; the CR was observed after $16 \mathrm{~h}$ application. 


\section{Pain}

According to several recent authors $(26,28)$, only minor discomfort occurs, but other authors apply an anaesthetic routinely $(25,32)$. In the present authors' experience, some form of pain medication is practically always required. Oral pain relievers such as paracetamol, naproxen and tramadol are often insufficient. Topical application of Emla ${ }^{\circledR}$ cream and lidocaine infiltration were applied with varying success. 5-Aminolaevulinic-acid-PDT was particularly painful for two patients with BCC on the nose, illuminated after 16-19 h of ALA application. Only Emla ${ }^{\circledR}$ was applied, which was not completely effective, and the pain in one case lasted for several days after the treatment.

\section{Possible improvements}

Although the high initial $\mathrm{CR}$ rates of topical ALA-PDT have been reported before $(28,29)$, recurrences occur and the histological response rates are lower $(25,26,33)$. Also, the CR rates of nodular BCC are less favourable. Messmann et al (34) and Hua et al (35) showed experimentally that the effect of PDT after systemic ALA administration can be increased by light fractionation. Van der Veen et al (36) showed that with one systemic ALA dose, the PDT effect could be increased when a second illumination was given, following re-appearance of $\mathrm{PpIX}$ fluorescence $1-2 \mathrm{~h}$ after the fluorescence had been photobleached by the first illumination. These effects may also occur after topical ALA. Other possibilities for improvement are the use of DMSO, EDTA $(27,29)$ or desferrioxamine $(32)$.

\section{CONCLUSIONS}

Photodynamic therapy using topical ALA application yields high CR rates in superficial BCC. Less favourable response rates have also been reported in the literature, in particular for nodular lesions. The differences may be the result of patient selection and duration of follow-up. Differences in treatment protocols may also play a role. Histological CR rates are lower than clinical CR rates. All authors, except Fijan (32), reported the same high response rates for Bowen's disease. In addition, actinic keratosis, cutaneous T-cell lymphoma $(37,38)$ and superficial squamous cell carcinoma (26) responds well to topical ALA-PDT.

Due to the photobleaching of the PPIX, the treatment is self-limiting. This effect also reduces the risk of overdosage in overlapping light fields when larger areas are treated. This self-limiting property of ALA-PDT also limits the therapeutic effect. This may be overcome by a longer ALA application combined with various forms of light fractionation $(35,36)$.

Cosmetic results were good to excellent. In two patients, keloid formation in the scar occurred after plastic surgery. 5Aminolaevulinic-acid-PDT in these patients caused no scar tissue, and the original tumour site could only be located using the pretreatment colour slides. In the authors' experience, pain during and after PDT is often a problem. A non-invasive method to relieve pain, that does not require injection of a drug in or under the lesion, would be desirable.

\section{REFERENCES}

1 Preston DS, Stern RS. Nonmelanoma cancers of the skin. N Engl J Med 1992, 327:1649-62

2 Weishaupt KR, Gomer CJ, Dougherty TJ. Identification of singlet oxygen as the cytotoxic agent in the photoactivation of a murine tumour. Cancer Res 1976, 36:2326-9

3 Wilson BD, Mang TS, Stoll $\mathrm{H}$ et al. Photodynamic therapy for the treatment of basal cell carcinoma Arch Dermatol 1992, 128:1597-1601

4 Buscaglia DA, Shanler SD, Mang TS et al. Phó́odynamic therapy with Photofrin II successfully treats basal cell carcinomas in patients with basal cell nevus syndrome. J Invest Dermatol 1994, 102:615

5 Robinson PJ, Carruth JAS, Fairris GM. Photodynamic therapy: a better treatment for widespread Bowen's disease. Br J Dermatol 1988, 119:59-61

6 Jones CM, Mang T, Cooper M et al. Photodynamic therapy in the treatment of Bowen's disease. $J A m$ Acad Dermatol 1992, 27:979-82

7 Razum N, Balchum OJ, Profio AE et al. Skin photosensivity: duration and intensity following intravenous hematoporphyrin derivatives, $\mathrm{HpD}$ and DHE. Photochem Photobiol 1987, 46:925-8

8 Dougherty TJ, Cooper MT, Mang TS. Cutaneous phototoxic occurrences in patients receiving photofrin. Lasers Surg Med 1990, 10:485-8

9 Kennedy JC, Pottier RH, Pross DC. Photodynamic therapy with endogenous protoporphyrin IX: basic principles and present clinical experience. $J$ Photochem Photobiol B: Biology 1990, 6:143-8

10 Divaris DXG, Kennedy JC, Pottier RH. Phototoxic damage to sebaceous glands and hair follicles of mice after systemic administration of 5-aminolevulinic acid correlates with localized protoporphyrin IX fluorescence. Am J Pathol 1990, 136:891-7 
11 Pottier RH, Chow YFA, LaPlante JP et al. Noninvasive technique for obtaining fluorescence excitation and emission spectra in vivo. Photochem Photobiol 1986, 44:679-87

12 Kennedy JC, Pottier RH. Endogenous protoporphyrin IX, a clinically useful photosensitizer for photodynamic therapy. J Photochem Photobiol B: Biology 1992, 14:275-92

13 Star WM, Versteeg AAC, Van Putten WLJ, Marijnissen JPA. Wavelength dependence of hematoporphyrin derivative photodynamic treatment effects on rat ears. Photochem Photobiol 1990, 52:547-54

14 Star WM. In vivo action spectra, absorption and fluorescence excitation spectra of photosensitizers for photodynamic therapy. I Photochem Photobiol B: Biology 1995, 28:101-2

15 Gijsbers GHM, Breederveld D, Van Gemert MJC et al. In vivo fluorescence excitation and emission spectra of hematoporphyrin derivative. Lasers Life Sci 1987, 1:29-48

16 Grant WE, Hopper C, MacRobert AJ et al. Photodynamic therapy of oral cancer: photosensitisation with systemic aminolaevulinic acid. Lancet 1993, 342:147-8

17 Loh CS, MacRobert AJ, Bedwell J et al. Oral versus intravenous administration of 5-aminolaevulinic acid for photodynamic therapy. $B r J$ Cancer 1993, 68:41-51

18 Szeimies RM, Abels C, Fritsch C et al. Wavelength dependency of photodynamic effects after sensitization with 5 -aminolevulinic acid in vitro and in vivo. $J$ Invest Dermatol 1995, 105:672-7

19 Elton RF. Cryosurgical advances and difficult cancers of the skin. In: Zacarion SA (ed) Cryosurgical Advances in Dermatology and Tumors of the Head and Neck. Springfield, Ill.: CC Thomas, 1977:150-70

20 Torre D. Cryosurgery in cancer. In: Andrade R (ed) Cancer of the Skin. Philadelphia: WB Saunders, 1976:1583-4

21 Menn H, Robins P, Kopf AW et al. The recurrent basal cell epithelioma. A study of 100 cases of recurrent, re-treated basal cell epitheliomas. Arch Dermatol 1971, 103:628-31

22 Sakura CY, Calamel PM. Comparison of treatment modalities for recurrent basal cell carcinoma. Plast Reconstr Surg 1979, 63:492-6

23 Hauben DJ. The biologic behaviour of basal cell carcinoma: analysis of recurrence in excised basal cell carcinoma. Plast Reconstr Surg 1982, 69:103-16

24 Scholten AN, Griep C, Davelaar J et al. Electron beam therapy is effective in the treatment of skin carcinoma; a comparison with superficial X-ray therapy. Ned Tijdschr Geneeskd 1996, 140(8):428-31

25 Cairnduff F, Stringer MR, Hudson EJ et al. Superficial photodynamic therapy with topical 5-aminolaevulinic acid for superficial primary and secondary skin cancer. Br J Cancer 1994, 69:605-8

26 Calzavara Pinton PG. Repetitive photodynamic therapy with topical delta-aminolaevulinic acid as an appropriate approach to the routine treatment of superficial non-melanoma skin tumours. $J$ Photochem Photobiol B: Biology 1995, 29:53-7
27 Orenstein A, Kostenich G, Tsur $\mathrm{H}$ et al. Photodynamic therapy of human skin tumors using topical application of 5-aminolevulinic acid, DMSO and EDTA. In: Brault D, Jori G, Moan J, Ehrenberg B (eds) Photodynamic Therapy of Cancer II. Proceedings of SPIE 1995, 2325:100-5

28 Svanberg K, Andersson T, Killander D et al. Photodynamic therapy of non-melanoma malignant tumours of the skin using topical delta-aminolevulinic acid sensitization and laser irradiation. Br J Dermatol 1994, 130:743-51

29 Warloe T, Peng Q, Heyerdahl H et al. Photodynamic therapy with 5-aminolevulinic acid induced porphyrins and DMSO/EDTA for basal cell carcinoma. In: Cortese DA (ed) Fifth International Photodynamic Association Biennial Meeting. Proceedings of SPIE 1995, 2371: 226-35

30 Szeimies RM, Sassy T, Landthaler M. Penetration potency of topical applied delta-aminolevulinic acid for photodynamic therapy of basal cell carcinoma. Photochem Photobiol 1994, 59:73 6

31 Peng Q, Warloe T, Moan J et al. Distribution of 5-aminolevulinic acid-induced porphyrins in noduloulcerative basal cell carcinoma. Photochem Photobiol 1995, 62:906-13

32 Fijan S, Hönigsmann H, Ortel B. Photodynamic therapy of epithelial skin tumours using deltaaminolaevulinic acid and desferrioxamine. $B r J$ Dermatol 1995, 133:282-8

33 Lui H, Salasche S, Kollias N et al. Photodynamic therapy of nonmelanoma skin cancer with topical aminolevulinic acid: a clinical and histologic study. Arch Dermatol 1995, 131:737-8

34 Messman H, Mlkvy P, Buonaccorsi G et al. Enhancement of photodynamic therapy with 5-aminolaevulinic acid-induced porphyrin photosensitisation in normal rat colon by threshold and light fractionation studies. Br J Cancer 1995, 72:589-94

35 Hua Z, Gibson SL, Foster TH et al. Effectiveness of $\delta$-aminolevulinic acid-induced protoporphyrin as a photosensitizer for photodynamic therapy in vivo. Cancer Res 1995, 55:1723-31

36 Van der Veen N, Van Leengoed HLLM, Star WM. In vivo fluorescence kinetics and photodynamic therapy using ALA-induced porphyrin: increased damage after multiple irradiations. Br J Cancer 1994, 70:867-72

37 Shanler SD, Buscaglia DA, Van Leengoed E et al. PDT with topical $\delta$-aminolevulinic acid for treatment of patch and plaque stage cutaneous T-cell lymphoma. $J$ Invest Dermatol 1994, 102:615

38 Wolf P, Fink-Puches R, Cerroni L et al. Photodynamic therapy for mycosis fungoides after topical photosensitization with 5-aminolevulinic acid. $J$ Am Acad Dermatol 1994, 31:678-80

Key words: 5-Aminolaevulinic acid; Protoporphyrin IX; Photodynamic therapy; Skin neoplasms; Basal cell carcinoma; Actinic keratosis 